This item was submitted to Loughborough's Research Repository by the author.

Items in Figshare are protected by copyright, with all rights reserved, unless otherwise indicated.

\title{
Pop-up governance: transforming the management of migrant populations through humanitarian and security practices in Lesbos, Greece, 2015-2017
}

\section{PLEASE CITE THE PUBLISHED VERSION}

https://doi.org/10.1177/0263775819891167

\section{PUBLISHER}

SAGE Publications

\section{VERSION}

AM (Accepted Manuscript)

\section{PUBLISHER STATEMENT}

This paper was accepted for publication in the journal Environment and Planning D: Society and Space and the definitive published version is available at https://doi.org/10.1177/0263775819891167. Users who receive access to an article through a repository are reminded that the article is protected by copyright and reuse is restricted to non-commercial and no derivative uses. Users may also download and save a local copy of an article accessed in an institutional repository for the user's personal reference.

\section{LICENCE}

CC BY-NC-ND 4.0

\section{REPOSITORY RECORD}

Papada, Evangelia, Anna Papoutsi, Joe Painter, and Antonis Vradis. 2019. "Pop-up Governance: Transforming the Management of Migrant Populations Through Humanitarian and Security Practices in Lesbos, Greece, 2015-2017". Loughborough University. https://hdl.handle.net/2134/10259654.v1. 


\section{Pop-up governance: transforming the management of migrant populations through humanitarian and security practices in Lesbos, Greece, 2015-2017}

\section{Introduction}

This paper introduces the concept of 'pop-up governance' as a way of conceptualising the practice-based, flexible and localised governance mechanisms that emerged in response to the migrant reception crisis at the south-east borders of the European Union (EU) between 2015 and 2017. With the escalation of the war in Syria, the number of people seeking to enter the EU from Turkey increased significantly during 2015. The EU responded by introducing the 'hotspot approach' to managing unauthorised migration. We propose the notion of 'pop-up governance' to describe the spatially bounded and allegedly temporary set of international governance practices that constitute the local implementation of the hotspot approach on the Greek island of Lesbos. The notion was born out of the empirical findings of [Project Title], the two-year ethnographic research project we conducted on Lesbos as part of our [Funder name]-funded research grant [Project title and Funder name and programme withheld for Peer Review]. More broadly, we argue that pop-up governance helps re-conceptualise governance as a set of practices that neither adhere to predefined rules nor constitute an exception, but instead develop or regress according to perceived demand. In this way, the paper helps advance our spatial and temporal understanding of governance: a crucial task at a time of ephemeral yet consecutive and heavily geographically clustered social and political crises.

Our four-strong team stayed repeatedly on Lesbos between September 2015 and December 2017, including five long-term stays and a series of briefer visits. During this time we conducted an ethnography of the hotspot approach. We visited key sites including migrant arrival points, registration centres, clinics and administrative HQs; recorded approximately two-hundred hours of ethnographic observation; interviewed thirty-six key actors including local community stakeholders, local and Greek government officials, EU and NGO representatives, and solidarity activists; and we analysed secondary data including European Commission and Greek government policy documents. We also produced a brief ethnographic film and mapped the hotspot approach in the broader EU context in the first research monograph dedicated to the issue [Authors, 2019].

Section 2 traces the evolution of the EU migration management regime. Its latest phase, marked by the European Commission's hotspot approach to migration management in emergencies, was consolidated following the EU-Turkey Statement of March $2016^{1}$. Section 3 then outlines our key fieldwork findings, which show the

\footnotetext{
${ }^{1}$ The EU-Turkey Statement (also known as the EU-Turkey Deal) was reached on 18 March 2016 and implemented two days later. It was intended to limit the mass arrival of migrants to Greece through Turkey. A key aspect was the return to Turkey of all migrants found to have entered the EU illicitly. The EU agreed to resettle, on a one-for-one basis, Syrians living in Turkey who had qualified for asylum and EU resettlement. The EU further incentivised Turkey with a promise of lessening EU visa restrictions for its citizens and by offering roughly $€ 6$ billion to the Turkish government in order for it to finance projects for Syrian refugees.
} 
workings of the hotspot approach. The logic of the hotspot, we argue, enacts border enforcement, but at the same time draws on securitisation and on the rationale of humanitarian emergency aid response. This logic gave birth to a particular kind of pop-up governance, and we use the following two sections to highlight the role of humanitarianism (section 5) and security (section 6) in the process. We conclude by calling for a re-evaluation of the role of seemingly ephemeral or geographically limited practices of governance in studies sitting at the intersection of migration, humanitarianism and security.

\section{EU migration management leading to, and in the age of the 'hotspot approach'}

Historically, European border policies have developed through mechanisms and practices-mostly invisible to the wider public-concerned with managing unauthorised mobility and avoiding mass transiting populations (Huysmans, 2000). Although today most refugees and other migrants are outside Europe, the continent has historically been central to the governance of international mobility. Indeed, the term 'refugee' originates from French Protestants escaping persecution in seventeenth-century France and seeking refuge elsewhere in Europe. In the early twentieth century, the first international arrangements to manage and support refugees were inaugurated with the League of Nations assisting hundreds of thousands of Russian 'White emigrés', who were fleeing the Bolshevik revolution. The second World War produced a new wave of involuntary mass population movement and displacement, prompting the fledgling United Nations to establish first the International Refugee Organisation and then, in 1951, the Office of the High Commissioner for Refugees (UNHCR).

The main multilateral agreement governing international population mobility has been the 1951 Refugee Convention and its 1967 Protocol, whose remit extends only to those meeting their strict 'refugee' definition. The management and regulation of the movement of other migrants has been left largely to the governments of individual nation states. The main exception is in Europe, where the 1985 Schengen agreement led to a reduction in border controls. Later on, the 'Schengen area' of border- and visa-free travel extended to 26 European countries through arrangements incorporated into the 1999 Treaty of Amsterdam.

From that year on the EU has also developed a Common European and Asylum System (CEAS), which became fully operational in 2015. Among other provisions, the CEAS includes the Dublin regulation, which stipulates that asylum claims should normally be processed in the country of first entry to the EU. Another key component of European mobility governance is the European Border and Coast Guard Agency, Frontex, whose role was upgraded in response to the migration events of 2015. Finally, the European Asylum Support Office is the EU agency responsible for supporting the implementation of the CEAS on the ground, including through training, capacity-building, and providing emergency support to EU member states subject to particular pressures on their asylum or reception systems. Since 1985, then, there has been a gradual, if often uneven Europeanisation of the governance of mobility within and across Europe's external borders. This leads up to the establishment of the hotspot approach to managing the 'exceptional flows' of 2015. 
The hotspot approach is both an evolution and culmination of European migration management policies, but it is also a policy fit for its time: a time when national and international policies swiftly adapt to new realities formed at equal speed by globalisation and neoliberalism, whether at the urban level (Harvey 2007), everyday living spaces (Brenner and Theodore 2010) or the world around us at large (Peck and Theodore 2016). In this era of expulsions (Sassen 2014) human migration and its management emerges as key in the future relationship between those who govern and those who are governed. In Europe, the Mediterranean and its islands have emerged as the most visible part of the EU border regime. Here, these practices have become part of a logistical operation (Pollozek and Pasoth 2019) all the while manufacturing emergencies, spectacularising enforcement, and intensifying detention practices (Campesi 2014, De Genova 2016).

The hotspot approach was marketed as the principal response to the European migrant reception crisis. It was jointly introduced by the European Commissioner for Migration, Home Affairs and Citizenship and the Greek administration. The approach was inaugurated at the Moria Reception and Identification Centre on Lesbos in October 2015, which coincided with our second visit to the island. In a matter of a few hours we witnessed the premises at Moria - a former military base - being transformed: they now looked ordered, clean, in a state of readiness. A parade of national and international journalists followed the officials. But behind camera-friendly, cheerful scenes, a major structural transformation was playing out.

The core strategy behind the hotspot approach is discussed in the European Agenda of Migration Management (2015) and subsequent European Commission communications $(2015,2016)$. Border enforcement at sea remained a key component, but was now to be accompanied by systematic identification and registration, as well as the completion of asylum procedures on the spot, before individuals move on. Conceptually, the hotspot approach was designed as a pressure regulator aiming at decelerating mobility. As a regulatory mechanism, the hotspot approach has a delegating function. It involves the hosting by a member state (in this case, Greece) of all relevant European agencies at the territorial border of the EU in order to bolster inter-agency cooperation and to centralize control over the external border. Once an area is declared a hotspot, the European Asylum Support Office, Frontex, Europol ${ }^{2}$ and Eurojust ${ }^{3}$ come in to assist the member state to swiftly identify, register and fingerprint incoming migrants (European Commission, 2015). The intention is that the four agencies will support member state authorities with registration, identification and removal of apprehended migrants (Frontex); the registration of asylum claims and preparation of relocation claimants (European Asylum Support Office); and the investigation and subsequent prosecution of crimes (Europol and Eurojust).

While Lesbos was declared a hotspot in October 2015, it was not until the implementation of the EU-Turkey statement in late March 2016 that we came to see the key aspects of this strategy in practice. Up to that point, the hotspot had been "more of a concept, an idea, less of an actual policy", as a top-level EU official on the island, who wished to remain anonymous, told us. But in March 2016 Moria received a total facelift

\footnotetext{
${ }^{2}$ EU agency for Law Enforcement Cooperation

${ }^{3}$ EU judicial cooperation unit
} 
and turned overnight into a pre-removal detention centre for failed applicants. Those who had arrived before March 20 were swiftly moved to the Greek mainland and subjected to regular (pre-hotspot) asylum procedures. Anyone arriving after this date was barred from leaving the island and was obliged to apply for asylum at the hotspot premises, using a new fast-track border procedure. This included a so-called 'one for one' mechanism: for every Syrian returned to Turkey, one would be resettled from Turkey to the EU-a resettlement supposedly matched by the speedy distribution of appropriate funds. It quickly became evident to us, and to officials and international NGO representatives on the island, that the implementation of the hotspot was going to be a messy affair. Overnight policy changes, chaotic and often clashing directives, and a glaring inability to implement these on the ground meant that previous conventions and guarantees-including the EU acquis (the rights and obligations of member states that arise from EU membership)—were now in great danger.

\section{Pop-up governance in Lesbos: some ethnographic reflections}

"At some point in early August 2015, there were over 100,000 people in the town of Mytilene 4 alone" recalls a key aide to the Mayor and the municipality's main communications strategist at the time. Pointing at the port area from where he was sitting for our interview, two months later, he described with full arm gestures the space covered by summer camping tents, then escorted our gaze to Sapfous square and finished by pointing to the steps of municipality building: "we had refugees sitting on these steps, even moving into people's gardens; we handed out water and food, we wanted to make sure the situation did not get out of hand". We began our fieldwork during that period, in the summer of 2015, in the middle of what he called the "biggest welcome operation in recent European history, and the biggest challenge we have ever faced as a local authority". Traffic from the Turkish coast had increased considerably during the hottest summer months, when seas are calmer and the daylight lingers on. Boats would land at different areas on the island's coast, with most of them washed onto its northern shores, where the distance from Turkey is shortest. One of the immediate challenges faced by local authorities at the time was registering new arrivals. "We engaged the police to perform registration and identification on the spot", he explains. As we witnessed ourselves during those first months, this meant that the police handed out plain A4 sheets of paper and asked those arriving to fill in their name and country of origin. The sheet was then to be presented to the port authorities to secure a ticket to mainland Greece. This was a temporary solution improvised by local authorities to keep the situation under control. It was the first such impromptu initiative that we witnessed, but not the last.

If we are to locate the inaugural moment for a more systematic, yet still improvised approach to the governance of migrants arriving at the Aegean Islands we need to go a little bit back in time. Greece's 2010 Action Plan for Migration Management effectively transposed the EU's 2008 Return Directive into Greek practice (Triandafyllidou 2010), as the fixation with deportations and Dublin returns guided policy development around borders and asylum at the time. 'Screening centres' were established in border zones and the First Reception Service was legally established (Law

\footnotetext{
${ }^{4}$ Capital and main port of Lesbos.
} 
3907/2011 of the Greek state), setting out the relevant identification and registration procedures. These centres were intended as sorting terminals, effectively separating those who were considered potential asylum seekers from others. The infrastructure and human resources required for setting up the First Reception Service (FRS) were put together with delays while the vast majority of those entering illicitly were to be subsequently transferred to nearby detention facilities. In practice, the non-implementation of returns and delays in screening resulted in a significant proliferation of detention facilities ${ }^{5}$ and prolonged administrative detention particularly around borders (Karyotis 2012). In April 2013 the Ministry of Citizen Protection, the government body responsible for borders and asylum at the time, introduced two Mobile Units (MD 11.1/1460) to reinforce registration and identification procedures. However, without being able to hire personnel ${ }^{6}$, the FRS remained understaffed. The project carried on with a handful of police officers while most of the operational activities involved in migrant screening, such as medical and interpretation services, were implemented via a state-third sector partnership model ${ }^{7}$. In essence, apart from fingerprinting, all other screening operations were left to subcontracted partners. According to one of our respondents with an employment affiliation to the FRS, when the numbers started picking up in February 2015, there was only one police officer registering 600 people per day on average. In addition to the Mobile Units, identification and registration ordinarily took place at the so called 'First Reception Centres' for digital fingerprinting, as required by the EU's EURODAC regulation. ${ }^{8}$

Back on Lesbos, with such meagre reception mechanisms put in place and given the profile of the incoming population in 2015-2016, ${ }^{9}$ the ensuing interpretation of the government's humanitarian obligations led to the establishment of an ad hoc two-tier registration system. As we witnessed ourselves, this two-tier system differentiated between those holding Syrian nationality and everyone else: the former received a six-month suspension from removal while the rest were issued a deportation order instructing them to leave the country within thirty days. When asked about this differentiation in the issuing of removal orders, our respondent, an aide to the Ministry

\footnotetext{
${ }^{5}$ For a more detailed map of Greece's closed camps and detention facilities please refer to: http://en.closethecamps.org/country/GRC

${ }^{6}$ The country's first bail-out agreement restricts significantly any new hirings of civil servants. This refers to the rules that were set as part of Greece's financial rescue agreement with the European Central Bank and the IMF. For more information please see: http://ec.europa.eu/economy finance/publications/occasional_paper/2010/pdf/ocp61 en.pdf

${ }^{7}$ As has been the case with Greece's Reception and Accommodation Service activities which has been supported by the European Refugee Fund until its recent incorporation to the EU's Asylum and Migration Fund, activities related to the FRS were subcontracted to two local NGO's. Although FRS service activities were largely funded by the External Border Fund (see Grant Agreement for the FRS Mobile Units: 'https://diavgeia.gov.gr/decision/view/\%CE $\% 92 \% \mathrm{CE} \% 99 \% \mathrm{CE} \% 97 \% \mathrm{CE} \% 94 \% \mathrm{CE} \% 99-\% \mathrm{CE} \% 9 \mathrm{C} \% \mathrm{CE} \% 9$ 53' The document is in English) additional donors, such as Norway, have been historically implicated to the running of FRS (see project description available at: http://eeagrants.org/project-portal/project/GR06-0001)

${ }^{8}$ EURODAC (European Dactyloscopy) is the EU's fingerprint database for asylum seekers. EURODAC is an essential instrument of the Dublin regulation, intended to ensure that asylum applications are processed by the EU country of first arrival.

${ }^{9} \mathrm{UNHCR}$ estimated at the time that around $60 \%$ of the incoming population fitted the profile of refugees.
} 
for Migration Policy, explained that its legal basis was "indisputable" and related it to Greece's obligations under International Humanitarian Law. The same explanation was also given during our interviews and discussions with UNHCR protection staff on Lesbos and in Athens. ${ }^{10}$ For much of 2015 the removal orders effectively functioned as "transit passes" (Franck 2017), allowing newcomers to move onwards to the mainland and the rest of Europe by presenting their registration document to authorities at the northern border of Greece with Macedonia. On Lesbos, the distinction practically resulted in multiple registration points where individuals were handled differentially according to nationality and protection category.

This differentiation was designed ad hoc, to fit and to try and remedy the chaotic conditions described above. The distinction between Syrians and non-Syrians was not based on any legal framework whatsoever. Nevertheless, the large number of arrivals meant that the police, local and national authorities felt they had to find a way to interpret their legal obligations. With dozens of boats carrying hundreds of people arriving every day on the northern shores of Lesbos, the need to identify and register everyone was paramount for the authorities. Yet so was the intention to keep these new arrivals moving. In this sense, these impromptu removal orders emerged from the conditions on the ground. They popped up as a governance tool to secure the fastest possible transit of those arriving towards the rest of Europe.

What we observed was a type of governance improvising its responses to a new situation, which had in turn been framed as an emergency. This new form of governance stemmed from the hotspot approach and functioned both as a magnifier and a corrector of perceived managerial failures and deficiencies. Greece's alleged failure on border controls, for example, was magnified by said proclaimed emergency. This alleged failure was in turn directly linked to the country's perceived lack of capacity to correctly identify and register arriving migrants. As our informant from the Ministry for Migration Policy explained, the pressure on Greek police to halt the practice of ink fingerprinting and switch to digital machines was so strong that it resulted in an obsession around registration processes. The digital fingerprinting of those arriving was highlighted by virtually all our interviewees from within public authorities. They all framed it as an absolute prerequisite of efficient border control.

In the time that we spent on the island, we witnessed the governance of migration as this was being improvised, hastily implemented, revoked at will, and drawn and redrawn in seemingly random and often conflicting steps. In short, the picture from the field was one of chaos: administrations and authorities operating beyond capacity, under budget, and with little sense of direction. And yet, at the same time, this impromptu decision-making, the retractable orders and obfuscated policies did have a very real effect: once the hotspot approach was in place, those who arrived on the islands were actually registered; European agencies did take over key functions otherwise revised for local and national authorities. We came to realise this was a certain type of 'impromptu governance', by which we mean a form of governance that takes form swiftly and even abruptly, while remaining tentatively retractable; a form of governance materialising at a certain, bound location-while its implications and impact are far-reaching. There is a

\footnotetext{
${ }^{10}$ The issue has also been picked up by relevant media outlets, see for example: http://newirin.irinnews.org/the-humanitarian-caste-system/
} 
double paradox, then, at the heart of pop-up governance: swiftness in its introduction is met by potentially equal swiftness in its retractability; while certain geographical limitations to its application contrast the potentially unlimited scope of its impact. The 'pop-up' notion has been associated with foldable, flexible, temporary and mobile structures and conditions: starting from something perhaps as innocuous as festival tents, but nowadays extending all the way to temporary and mobile retailing (Warnabi and Shi 2017), temporary urbanism (Ferreri 2015) and even flexible, interstitial and immersive geographies as a whole (Harris 2015): the 'pop-up' has in many ways come to be emblematic of a time when mobility and adaptability become equally paramount for survival-whether personal, collective or institutional. In response, we have made great inroads in understanding the process and cost of individuals, populations or businesses adapting to the demands of our times, from flexible labour (Strauss 2018) to camp geographies (Mould 2017). We recognise past models of governance are largely incapable of capturing, let alone responding to the fleeting nature of the present moment. And yet there is little progress in the study of how the structure and nature of governance is also changing as a result. We introduce 'pop-up governance' in an attempt to fill this conceptual gap. We understand pop-up governance as a distinctive form of governmental response to a perceived crisis, emergency or event. While the precise configuration of agencies, processes and policies involved will vary depending on the objects of governance, we identify the following features as typical of pop-up governance in the case of Lesbos:

1. It is narrowly focused on a specific problem or event. Throughout our elite interviews, a consistent theme was authorities' need to prioritise dealing with the specific task-at-hand: "the priority of government", told us a local authority coordinator (June 2017), "should first and foremost be decongestion of the island and fast tracking of the procedures".

2. It is spatially targeted, but with a scope to be replicated elsewhere with suitable adaptations. Authorities understood the challenge of a constantly volatile and flexible situation, and the subsequent need "to be agile and adaptable: as you know, routes change all the time", told us a European Union representative on the island (December 2016).

3. It is intended to be temporary, in the expectation that conventional governance will be restored once the problem has been controlled.

Reception centres in Lesbos were always meant to be a temporary measure: "local society is opposed to the longer establishment of yet another reception centre", claimed a national government representative elected in Lesbos. "Our effort is to appease the local society and assure them we will not be forever stigmatised by this event" (December 2016).

4. It does not suspend normal governance and claims not to revoke rights. Unlike a 'state of exception', pop-up governance is meant to facilitate and expedite 'normal' governance and to supposedly enable the exercise of rights. "The problem is not with the procedures, the problem is how these are implemented - in other words, how fast" (local authority coordinator, June 2017). 
5. It legitimates itself by claiming to fill a temporal and spatial gap in the capacity of governance. "We had to learn to work together [with our FRONTEX colleagues] in a very short time... We would not be able to patrol without them and these extra resources" (Greek coast guard, June 2017).

6. It is mobile in a two-fold sense: First, it aims to be a nimble-footed response to events as the emerge 'on the ground', and second, to then become capable of redeployment and replication. "We have trained EASO caseworkers who will be able in turn to train others as and when needed" (EASO spokesperson, December 2016).

7. It involves reaction to unforeseen events. Unlike other forms of governing emergencies involving anticipation (Adey and Anderson, 2011), pop-up governance highlights improvisation, rather than implementation of prepared plans. Here, impromptu synergies take shape: "when we cannot intercept dinghies headed to the rocky coast, we ask volunteers to help. Our boats are too large, so we often rely on volunteers' smaller vessels", told us a Greek Coast Guard officer (June 2017). And yet the vast majority of volunteers refused to cooperate with authorities, showing the tension in these new synergies.

8. It may involve the formation of new spaces of governance. These include temporary command centres, people and information processing facilities, transport infrastructure and service provision: "one of our biggest challenges in setting up the Reception and Identification Centre was to establish personnel as coordination points and to interlink our databases" (Reception and Identification Service liaison, June 2017).

In the following sections we reflect on some of these aspects of pop-up governance in relation to two key features of the management of migration in Lesbos: humanitarianism and security.

\section{The humanitarianism of pop-up governance}

Humanitarianism has been studied as a form of governance that sees the preservation of life as the highest moral imperative (Fassin 2012). Humanitarian governance is here understood both in relation to the ways in which it seeks to manage order populations by alleviating suffering and in its function as ordering chaos in order to be able to govern and alleviate suffering.. Walters (2012) was the first to note the transformation of territorial borders into spaces of humanitarian government. With his 'humanitarian border' notion, Walters tries to capture not a sequence of securitisation and humanitarianisation of the border but rather "the ways in which tactics and counter-tactics play themselves out at the molecular level" (Walters, 2012: 147). The invocation of humanitarian emergencies at borders legitimises forms of intervention by humanitarian actors sub-contracted by the state to perform a series of functions typically belonging to the remit of the state itself, particularly health care and welfare support. In biopolitical terms, the tension between security and humanitarian logics has been likened to an autoimmune disorder of the body (Vaughan-Williams, 2015), as "although border 
security may appear to preserve life via humanitarian practices, it also threatens the same life it is supposed to protect" (2015: 119). In the case of the Mexico-US border, this has successfully resulted in the humanitarian militarisation of border enforcement through a dedicated state discourse that counters arguments about the violence of border enforcement (Williams, 2015). Variations in the intensity and tactics of this phenomenon have occurred elsewhere too. In both the EU and Australia, for example, discourses around saving lives by stopping boats have produced migrant subjectivities that become governable through the urgency to act in order to prevent more deaths (Little \& Vaughan-Williams, 2016). But it is equally important to highlight the multiple ways in which humanitarian actors also become complicit in the production of governable population through ordering at the border. What our ethnographic research on Lesbos unveiled was that humanitarianism, as a central feature of the pop-up governance of migration, accomplished ordering through implementing systems of classification-which ultimately came to blur the lines between care and control.

UNHCR's map (Figure 1) points to such a classification and channeling mechanism set up by humanitarian actors and ultimately coordinated by UNHCR itself.

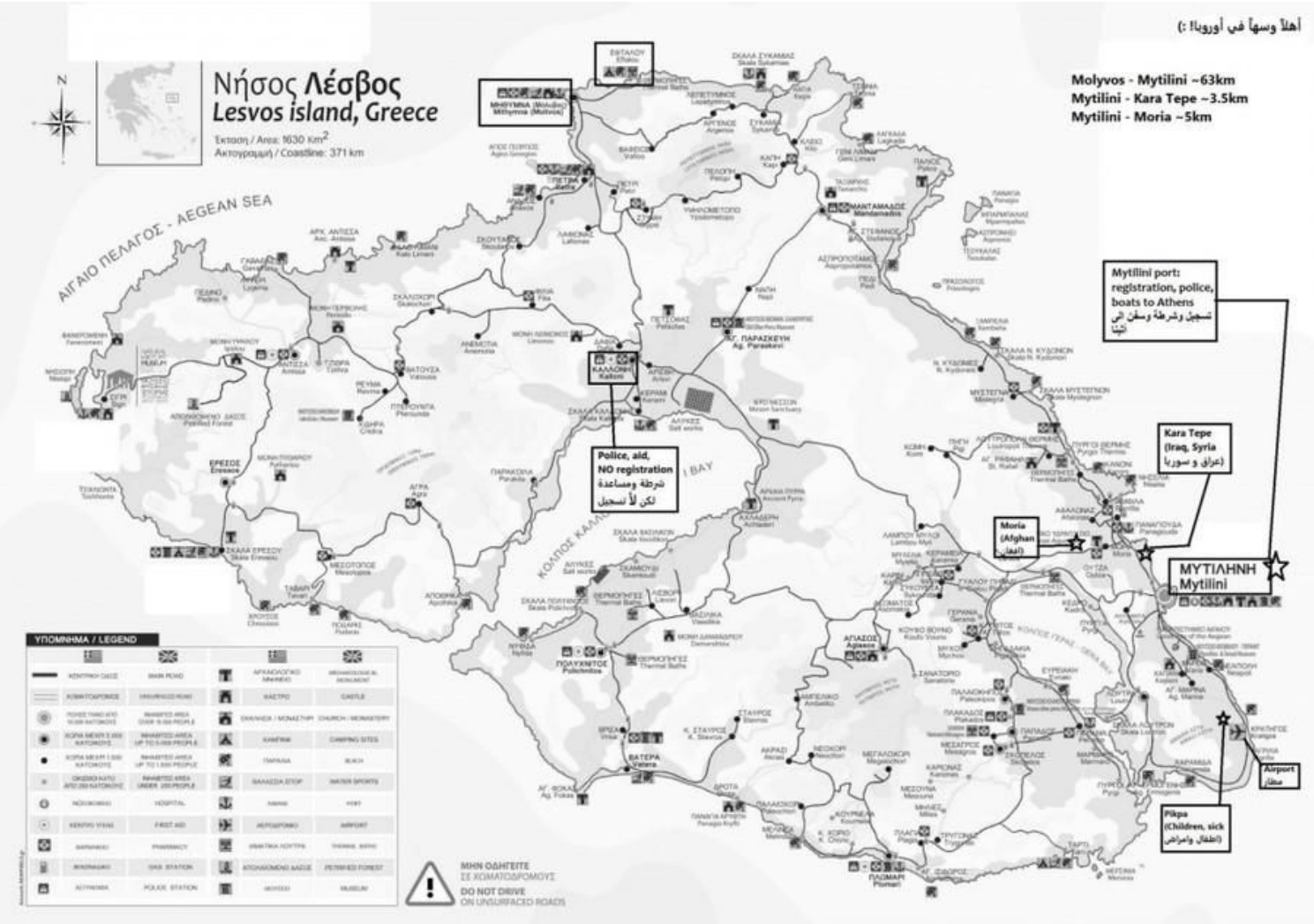

Figure 1 Source: UNHCR and MapAction - image shared under a Creative Commons 3.0 license.

The registration and identification of migrants has long been a key objective of the EU's border controls (Guild \& Carrera 2013). In EU policy jargon, the process of registration and identification upon arrival at territorial entry points is commonly referred to as 
'screening' or 'first reception'. This is a bureaucratic procedure loaded with logistical and administrative obstacles. With almost 700,000 people crossing into and through Lesbos during the summer of 2015, this logistical challenge was simply too great for the existing Frontex and national police units. The UNHCR (UN's refugee agency) came to fill in the gap by offering additional human resources and know-how in humanitarian border management.

In August 2015, calling for a response equal to that mounted in humanitarian disasters, ${ }^{11}$ the UNHCR identified two operational priorities: first, the strengthening of Greece's first-line reception capacity; and second, expedited access to the asylum system within the framework of the EU's then nascent hotspot approach and relocation mechanism. The motivation behind the UNHCR's emergency appeal was grounded in humanitarian concerns about overcrowding and congestion. The need to provide for orderly transit through the island was argued in conversations both at headquarters and among humanitarian personnel on the ground. In supporting the 'decongestion' of the island as an aid strategy, UNHCR advocated the need to speed up previous procedures for the identification and registration of new arrivals.

The immediate challenge was transferring hundreds of thousands of refugees from the landing points on the north side of the island to the official registration sites on the east (see figure 1). Besides humanitarian relief items and food, these individuals and families demanded reliable information and legal advice regarding their next steps. Humanitarian personnel recognized the limitations of an aid relief approach in the face of a moving population with high chances of being granted refugee status. In the words of one of the UNHCR emergency coordinators, "their needs are very different and our approach should be flexible; we must quickly adapt to the challenge" (interview with UNHCR protection officer, October 2015).

Pallister-Wilkins (2019) describes the complications migrant mobility posed to humanitarian practice in Lesbos as a "form of 'sticky' triage" that is "based on the sorting of bodies according to suffering and need" (2019: 373). This sorting of migrant bodies adheres to logic and method of categorisation and classification according to their nationality and their 'vulnerable' classification. It takes place in a web of physical nodes en route from the landing points to the official registration centers south east of Lesbos. Known as transit points, they serve as in-between stations, spaces of assembly and traffic control, in which migrants are kept and discharged at regular intervals. We documented three core such spaces in the north of the island: transit point Mantamados, UNHCR transit camp in Skala Sikaminias and Club Oxy, just outside the village of Molyvos. We systematically observed practices of nationality and vulnerability assessment, carried out by humanitarian personnel along the transit route from the northern shores to the official registration points. Yet these practices also generate certain politics of space (Massey, 2005): as the places where migrant triage happens, they must be understood in relation to places of registration elsewhere on the island. Together, they form a web of spatial ordering of migrant movement.

$\underline{11}$ http://www.unhcr.org/news/press/2015/8/55c48ea69/unhcr-warns-deepening-refugee-crisis-greece-calls-u rgent-bold-action.html 
From our interviews with humanitarian personnel we were informed that data collected in transit points served to prioritise certain nationalities and vulnerabilities, but also to refer migrants to the corresponding administrative procedures. Both nationality categorisation and vulnerability classification became a defining aspect of the implementation of the hotspot approach and the EU-Turkey statement (Authors, 2018).

The humanitarian shift from sea rescues to decongesting the island made migrants more knowable in the process - and thus more governeable. In this way, the space of humanitarian border management was shaped by the imperative to properly identify nationality and prioritise according to vulnerability. While registration and border controls are firmly grounded in the notion of security, not all humanitarian action is at odds with security goals. Basaran (2014) employs the notion of humanitarianism under conditions of security in her discussion of the criminalisation of rescue in the central Mediterranean Sea. In modern liberal democracies, she argues, states seek to govern the humanitarian sentiment in the name of security. While states may discourage humanitarian rescue in the name of security, they are not opposed to humanitarian ordering. In the case of Lesbos, the humanitarian space which emerged there did not draw on the theme of preserving life through rescue, but rather, on creating a space where humanitarian action was warranted primarily as a response to an emergency-without disturbing the project of border controls.

Ordering at the border space intensified as the pace of arrivals slowed down. With the official launch of the hotspot approach, the discourse shifted considerably from decongesting the island towards optimising identification and registration procedures and producing results. However, owing to the lack of EURODAC ${ }^{12}$ registration equipment and personnel, authorities resorted to a reorientation of existing resources. By November 2015, Frontex had deployed 325 staff across Greek islands-87 of which were to support identification and registration on Lesbos, including through mobile registration units. Mobility between the two migrant camps, Kara Tepe and Moria, became restricted and fences reinforced. An informal campsite sprawled next to Moria, bearing witness to the real effects that the goal to identify, register, fingerprint and administratively process all those individuals at once had on the bodies and lives of transiting migrants. Already during the early months of its operation, the hotspot replicated conditions that humanitarian agencies were called upon to resolve in the first place. The humanitarianism of decongestion was designed to manage lives on the move; and while it made humanitarianism complicit with border control, it nonetheless operated under the principle of creating an environment where the delivery of care was possible. Under the hotspot approach, humanitarian actors became gradually restricted in their ability to provide relief. Meanwhile, the logic of categorisation by need and nationality had in turn been successfully incorporated into the architecture of the hotspot approach.

\section{Security practices in pop-up governance}

The discourse over security has long been argued to have shifted toward a diversified set

\footnotetext{
${ }^{12}$ During the 2015 crisis all new arrivals were required to be digitally fingerprinted but this was not always possible due to the lack of proper equipment, personnel and/or training on the islands, including Lesbos.
} 
of practices (Cote-Boucher et al., 2014) owing to the varying and often contradictory aims of actors involved in policing borders today. Knowing what these actors actually do helps sustain a productive link between "complex relationships with security discourses, legal regimes and policies", which in turn bring into closer view the nuances of contemporary bordering (2014: 196). In a similar vein, Bigo (2014) demonstrates how these practices of border control are embedded in the daily routines of surveillance professionals, military and security personnel. In the context of the EU's maritime borders, humanitarian border security practices become legible in Frontex's politics of rescue through interdiction (Moreno-Lax, 2018), as well as in the practices of legal exclusion (Basaran 2014). The peculiar presence of human rights and humanitarian ideals within border policing practices has been speculated to stem from a professional and personal understanding of duty to humanity (Jeandesboz and Pallister-Wilkins, 2016). Elsewhere, Jill Williams (2015) shows how the informal actions of care to injured migrants made by US border patrol officers have, through the years of stricter and securitised discourse, transformed Border Patrol protocols concerning interacting with migrants, leading to further criminalisation of humanitarian aid volunteers.

The portrayal of migration as a security threat has been the subject of scholarly literature for sometime (Bigo 2002; Huysmans 2000; Aradau 2004). We agree with the sociological approaches to security that consider security practices (such as the action of border guards and/or Frontex), not discourses, to be strong securitisation indicators (Cote-Boucher et al. 2014). Within border zones, security practices result from ordinary law and exceptional politics alike (Basaran 2008). It is in the context of migration management under humanitarian border security (Vaughan-Williams, 2015) that the hotspot approach is justified and pop-up governance arrives. In this context, the mismatch between the migrants' real-life experiences of border policies and the humanitarian rhetoric that accompanies them becomes an integral part of the current biopolitical governance of mobile populations (Little \& Vaughan-Williams 2017).

\section{Crimes and non-crimes of assisted transportation}

The security practices of pop-up governance are characterised by the criminalisation of certain humanitarian activities under the premise of 'anti-smuggling' laws. Greece's anti-human trafficking legislation prohibits individual and commercial vehicle owners from transporting individuals lacking proper identification. Yet migrants landing at the northern shores of Lesbos had to find a way to reach the registration centers, 68 kilometers to the south. During the first months of 2015, individuals willing to help migrants by offering a lift in their private vehicles did so without interference from the police, but at their own risk. UNHCR-led advocacy efforts ${ }^{13}$ resulted in an amendment of this legislation in June that year. The ensuing exception from penalisation regarding transport assistance of those arriving was, however, authorised on the condition that it would serve migrants' admission to legal procedures. This was essentially a reference to the administrative formalities regarding illegal entry and first reception. This exception was only permitted after competent authorities (the police or the coast guard) had been

\footnotetext{
${ }^{13}$ Statement of finding following field visits of the Greek Ombudsman to the islands of Kos, Leros, and Lesbos between 16-25/06/2015: http://www.synigoros.gr/resources/150727-stp.pdf
} 
duly informed. In other words, transporting newcomers was only allowed by 'exception', and provided it actually facilitated the registration process. In practice, the implementation of this regulation was largely left to the discretion of the police and was further hampered by the inability or unwillingness of interested parties to access and inform the authorities. The exception was not extended to taxi drivers. As a result, the initial efforts including volunteer-organized convoys driving women, children, and the elderly to transit centres in Molyvos or Skala Sikaminias were quickly replaced by organised coach transport from transit centers and assembly points in the north, to the registration sites of Mytilene, implemented and funded by the International Rescue Committee, UNHCR and others.

Transporting individuals from one side of the island to another does not amount to criminal smuggling in the eyes of the authorities at all times and legal provisions can develop and regress according to demand. These new practices of governing mobility on the island of Lesbos effectively decriminalised the transportation of persons, by making it work for the purpose of identification. It also distinguished between official humanitarian assistance and unofficial or voluntary acts of compassion, decriminalising the former while criminalising the latter-working towards "the potential of law to produce collective indifference" (Basaran 2015: 210). Several interviewees from civil society organisations reported intimidation by the police. The practice of compulsory registration of all activist and civil society organisations offering assistance and the gradual criminalisation of unofficial humanitarian assistance was based on the mantra of "central coordination" (interview with government MP, November 2015). On December 15, 2015, the Commission published an "implementation report" on the hotspot approach that requested the centralised coordination of relevant governmental and non-governmental players involved in the hotspot locations. As a result, police harassment and closure of squats and soup kitchens intensified. As Statewatch reported ${ }^{14}$, the demand for central coordination of humanitarian activities became inscribed in law as early as January 2016, less than six months after the launch of the hotspot approach.

\section{Experimenting with detention practices}

Prior to the inauguration of the hotspot (in October 2015) the Moria registration site was operated by Greek authorities in partnership with UNHCR. At the time, detention was limited to a hundred or so places in a small compound within the camp. Syrian nationals were registered in Kara Tepe and their nationality was quickly identified, as the majority were holding passports, thereby speeding up the process. After that date, registration routines were reorganised, and Kara Tepe no longer operated as a registration site. There were two separate sites for registration in Moria, a queue forming at the formal entrance where Syrian families waited to be registered, a second for Syrian men, Yemen and Somali nationals and a third at the side and at the back of the facility with Iraqi, Afghani and all remaining nationalities. Vulnerable groups such as pregnant women and single parents were prioritised regardless of their nationality. Registration queues were managed by the police and for the most part they seemed endless and stalling. During our frequent

${ }^{14}$ http://www.statewatch.org/news/2016/jan/eu-med-crisis-criminalising-civil-society.htm 
visits, we had good opportunities for conversation. It did not take long for us to realise that getting at the front of the queue was a status attainable by several means-including aggression or payment. On another instance, in an effort to discipline those further down in the queue, a police officer picked out a male individual and assign them the role of 'peacekeeper': an order manager in return for quicker registration. Along the queue of Afghan nationals, there were sometimes men carrying sticks (ravdia), handed to them by the police to use as a disciplining tool. This was understood to be a culturally appropriate form to crowd control in Moria since Afghani people, as one police officer put it, "obey the stick" (interview with police officer, December 2015). These otherwise uninformed views and improvised methods of crowd control by frontline personnel nevertheless contributed to security practices that were overall effective: the security apparatus expected the unexpected in terms of the conduct of this personel; or in other words, their uninformed views and impromptu and otherwise inappropriate methods were a perfect fit for a system of governance that was equally impromptu, a pop-up structure that could appear and vanish with ease.

Yet these techniques generated feelings of arbitrariness and injustice to those waiting. They also became the precursor for the usage of more violent methods of crowd control, particularly when conditions in the hotspots deteriorated throughout 2016. For example, every shift change of the team of officers guarding the gates at the front of the queue, for which a police bus was needed, meant the dismantling of the queue-as the bus had to go through the queueing area. In the time it took the police bus to leave in a cloud of dust, people would rush back and struggle to get to their old place in the queue or fight to cut the line and get to the front. This eventually led to scuffles and riots, allowing the police to intervene using violent crackdown methods.

The launch of Moria as a hotspot in October 2015 signified the gradual incorporation of a new management approach into the operations of the first reception centers. The prefabricated containers of the registration and identification centre were now surrounded by barbed wire fencing, typical of globalized detention center aesthetics (Flynn, 2017). The closed facility was now operated by the Greek Police, while registration and identification were managed by Ministerial and Frontex personnel inside. Behind these locked compounds, aside from the UNHCR and EU institutional representation, a certain number of local NGOs operationalised medical and interpretation activities as implementing partners. There were additional spaces reserved for unaccompanied minors, detained on the premise that they were in a vulnerable age and stood the risk of falling victim to unscrupulous smugglers and other criminal networks.

The hotspot approach provided the pretext not only for expanding the infrastructure and the legislative grounds for detention ${ }^{15}$ but also for introducing a

\footnotetext{
15 Art. 46 of Law 4375/2016 provides five grounds to detain migrants: 1) in order to determine his/her identity or nationality, 2) to "determine those elements on which the application for international protection is based which could not be obtained", 3) in case "that there are reasonable grounds to believe that the applicant is making the application for international protection merely in order to delay or frustrate the enforcement of a return decision" (return decisions are in practice broadly issued to new arrivals and
} 
number of pilot detention programmes. In particular, our informants reported that sometime in December 2015 a new police verbal order was issued regarding the detention of nationals of North African countries in Greece. On our last visit at the end of 2016, an informant working as a psychologist for detainees in the hotspot told us that the pilot project had been extended to all nationalities understood to have less than $25 \%$ recognition rate success. When Law 4375/2016 came into force, following the readmission agreement between Greece and Turkey, grounds for detention were expanded to include those believed to be applying for asylum for the purpose of avoiding removal. According to interviewees working as legal aid professionals in Lesbos, migrants often complained about being registered wrongly by Frontex as belonging to low-recognition rates nationalities. During the months leading to the EU-Turkey statement, Moria had gradually built its capacity as a pre-removal center. The rationality on detaining persons due to their nationality and recognition rate had become standard practice, despite the fact that the removal of those individuals within the three-month timeline was in virtually all cases impossible. The Moria pre-removal center was organised by different sections, according to nationality and ethnicity. With the implementation of the 'hotspot approach', and as envisaged in the readmission agreement between Greece and Turkey, the simple act of arriving on the island amounted to grounds for automatic detention. Virtually overnight, a new security regime popped up. This regime was based on the assumption that belonging to a nationality with a low rate in the recognition of asylum applications was prima facie evidence of an attempt to abuse the asylum system. Security practices reliant upon assumptions and statistical inference became a tool of governance that was now morally and legally legitimised through the work of security professionals in the hotspots.

\section{Conclusion}

We started our fieldwork on Lesbos thinking we were faced with an evidently large-scale version of a crisis of migration management, but with an equal sense that this crisis was not unprecedented - that it followed patterns found elsewhere in the past. In studying the Moria registration and detention camp, for example, we looked back at studies of reception camps and assembly points set up to fulfil border control and interim hospitality. These have been widely studied both as a technology of power and control and as a technology of care in the management of displacement in the global borderlands (e.g. Agier 2011; Hyndman 2008).

Soon enough however, we realised that the role of humanitarian actors in EU border enforcement was crucial and new, and we looked at concurrent scholars attaining to this (Cuttita 2017; Pallister-Wilkins 2019; Stierl 2017). Our own field research unveiled the use of new spatial and temporal governance strategies in managing transit through the island. The humanitarian intervention which established the separation of protection-worthy subjects set the stage for the categorisation and channeling of incoming populations. This followed a logic deeply embedded in the international 
protection regime, as a mechanism of partition, identification and registration (Tazzioli and Garelli, 2018). Prior to the inauguration of the hotspot, registration processes shifted between the two main transit camps - Kara Tepe and Moria. Time of arrival played a key role in the administrative treatment of each individual, and nationality was used as a method of assessment of the legitimacy of their claim. Following the hotspot inauguration, and through the winter and spring months leading to the enforcement of the EU-Turkey statement, temporality and differential nationality treatment became the established model of management of the asylum process on the island. Those who arrived after the EU-Turkey statement fell into different procedural tracks than the ones already there. The applicants' nationality was further encoded into the asylum procedure through differential treatment based on the statistical probability of different nationalities gaining international protection. These spatial strategies for the management and administration of the increased arrivals and population transit had already introduced and promoted the differentiation of individuals into protection categories and levels of vulnerability. Soon enough, they became institutionalised through the implementation of the hotspot approach.

We witnessed that security practices were at the centre of attention in Lesbos, and we looked at previous works on migration and its association with questions of security (e.g. Basaran 2008; Bigo 2002; Huysmans 2000; Vaughan-Williams, 2015) to see if they could help shed light on the particular governance turn playing out in the island. In Lesbos, it was not always easy to discern between the humanitarian and the security practice. For example, assembly points and transit camps erected to manage the emergency were socio-spatial materialisations of the securitised border, a border that produced frequent emergencies in turn. Take for instance the deaths caused by attempts to warm up tents in Moria during the harsh winter of 2017. The emergency winterisation of the camp that ensued, by means of replacing tents with containers, temporarily appeased protests against the deadly effects of encampment. For quite some time, the practices of humanitarian professionals in their approach to ordering disorder on the island were directly aligned to the practice of security professionals tasked with policing the border. By the time the hotspot approach was launched, the securitised humanitarian space that emerged on the island molded even more into the needs of identification and registration, while humanitarian action became progressively marginalised.

In our conversations with and observations of humanitarian and security professionals, we realised a new governance turn was under way, characterised by swiftness and geographical precision in the deployment of governance mechanisms in order to match a particular crisis: a certain type of pop-up governance was born on the island. This form of governance took form swiftly and abruptly-on the day of the EU-Turkey deal, and the ensuing inauguration of the European Commission hotspot approach approach in March 2016. This remained tentative and retractable throughout. Pop-up governance materialised at a certain, bound location-the island of Lesbos in our case-yet its implications and impact are far-reaching. Earlier in the paper we defined this as a double paradox, where swiftness in introduction were met by equal swiftness in retractability; and where geographical limitations contrasted with the potentially unlimited impact of pop-up governance. Just like its unlikely sibling from the retail 
world, pop-up governance may also act as a very particular kind of an incubator: a trial run that, if and once successful, may be deployed elsewhere, at a larger scale.

Some may argue that a flexible, time-limited and adaptable form of governance was the only realistic way forward for handling this unprecedented crisis. Undoubtedly, the arrival of around 400,000 individuals ${ }^{16}$ over a short period of time presented considerable logistical challenges for authorities. The assistance and know-how provided by humanitarian organisations may have indeed helped relieve the burden of managing an orderly transit through the island. The argument this paper is making is not against the necessity of measures and logistical solutions to assist refugees in a humane manner. At the same time however, the humanitarian solutions implemented on the island during this period were anchored on the tradition of containment and control, as embedded within the humanitarian government of populations around the world. What played out on Lesbos was yet another expression of the attempt of humanitarian agencies to adapt to the logic of the securitised border whilst at the same time enriching that very logic with processes of differentiation and categorisation. With the introduction of the EU-Turkey Statement (March 2016) and while humanitarian actors were pushed aside, processes of categorisation according to nationality intensified while protection standards went out of the window. The territory of the nation-state was split in two: different legislation and standards applied at the outer 'hotspot' edges than on the Greek mainland. In the long run, and due to delays in both returns and the relocation of applicants to other European countries, the island hotspots and mainland Greece have since turned into spaces of indefinite containment. Now, more than ever, the future of the European protection regime is at the mercy of European border controls.

It is for these reasons that the 'hotspot approach' and the logic of pop-up governance it represents are not simply an attempt to territorialise the governance of human mobility at the fringes of the state. They are also, and in many ways much more crucially, an attempt to make the governance of human populations mobile in itself; to surpass the so-far dominant distinction between normalcy and the emergency by setting out geographically and chronologically finite models of governance that can nevertheless be replicated at will to meet demand-whether perceived or real. It is also, and much more crucially, an attempt to make mobile the governance of human populations as a whole: that is, to alter the very essence of the state. The core principles of the 'hotspot approach' and its ensuing pop-up governance logic as these transpired in Lesbos point at a much more generalisable and generalised form of governance stemming from, and yet greatly surpassing isolated questions of humanitarianism, security, or indeed migration: the pop-up governance born in Lesbos points at a future direction for the governance of vulnerable populations and contemporary socio-political crises alike.

\footnotetext{
${ }^{16}$ https://www.unhcr.org/protection/operations/5645ddbc6/greece-factsheet-lesvos-island.html
} 


\section{References}

Adey P and Anderson B (2011) Event and anticipation: UK civil contingencies and the space-times of decision. Environment and Planning A 43: 2878-2899.

Agier M (2011) Managing the Undesirables: Refugee Camps and Humanitarian Government. Cambridge: Polity.

Aradau C (2004). Security and the democratic scene: desecuritization and emancipation. Journal of International Relations and Development 7(4): 388-413.

Basaran T (2008) Security, law, borders: spaces of exclusion. International Political Sociology 2(4): 339-354.

Basaran T (2015) The curious state of the good samaritan: humanitarianism under conditions of security. In: Kinvall C and Svensson S (eds) Governing Borders and Security: The Politics of Connectivity and Dispersal. Abingdon: Routledge.

Basaran T (2014) Saving Lives at Sea: Security, Law and Adverse Effects. European Journal of Migration and Law 16(3): 365-387.

Bigo D (2002) Security and immigration: Toward a critique of the governmentality of unease. Alternatives 27: 63-92.

Bigo D (2014) The (in)securitization practices of the three universes of EU border control: Military/Navy - border guards/police - database analysts. Security Dialogue 45(3): 209-225.

Brenner N and Theodore N (2005) Neoliberalism and the urban condition. CITY 9(1): 101-107.

Campesi G (2014) Frontex, the euro-Mediterranean border and the paradoxes of humanitarian rhetoric. South-East European Journal of Political Science 2(3): 126-134.

Cote-Boucher C, Infantino F and Salter Mark B (2014) Border security as practice: an agenda for research. Security Dialogue 45(3): 195-208.

Cuttita P (2017) Delocalization, humanitarianism, and human rights: The Mediterranean border between exclusion and inclusion. Antipode 50(3): 783-803.

De Genova N (2016) The "crisis" of the European border regime: Towards a Marxist theory of borders. International Socialism 150.

European Commission (2015) A European Agenda on Migration.

https://ec.europa.eu/home-affairs/sites/homeaffairs/files/what-we-do/policies/european-ag enda-migration/background-information/docs/communication on the european agenda on migration_en.pdf 
European Commission (2015) The Hotspot Approach to Managing Exceptional Migratory Flows.

http://ec.europa.eu/dgs/home-affairs/what-we-do/policies/european-agenda-migration/bac kground-information/docs/2 hotspots_en.pdf

Ferreri M (2015) The seductions of temporary urbanism. Ephemera 15(1): 181-191.

Fassin D (2012). Humanitarian Reason: A Moral History of the Present. Berkeley: University of California Press.

Flynn M (2017) There and back again: on the diffusion of immigration detention. Journal on Migration and Human Security 2(3): 165-197.

Franck AK (2017) Im/mobility and deportability in transit: Lesvos island, Greece, June 2015. Tijdschrift voor Economische en Sociale Geografie 108(6): 879-884.

Guild E and Carrera S (2013)'EU borders and their controls. Preventing unwanted movement of people in Europe? Center for European Policy Studies.

https://www.ceps.eu/system/files/No $\% 206 \% 20$ EU\%20Borders $\% 20$ and $\% 20$ their $\% 20$ Cont rols $\% 20$ revised.pdf

Harris E (2015) Navigating pop-up geographies: urban space-times of flexibility, interstitiality and immersion. Geography Compass 9(11): 592-603.

Harvey D (2007) Neoliberalism and the city. Studies in Social Justice 1(1): 1-13.

Huysmans J (2000) The European Union and the Securitization of Migration. JCMS: Journal of Common Market Studies 38(5): 751-777.

Jeandesboz J and Pallister-Wilkins P (2016) Crisis, routine, consolidation: the politics of the Mediterranean migration crisis. Mediterranean Politics 21(2): 316-320.

Karyotis G (2012) Securitization of migration in Greece: Process, motives, and implications. International Political Sociology 6(4): 390-408.

Little A and Vaughan-Williams N (2017) Stopping boats, saving lives, securing subjects: Humanitarian borders in Europe and Australia. European Journal of International Relations 23(3): 533-556.

Massey D (2005) For Space. London: Sage.

Moreno-Lax V (2018) The EU humanitarian border and the securitization of human rights: The 'rescue-through-interdiction/rescue-without-protection' paradigm. JCMS:

Journal of Communication Market Studies. 56(1): 119-140.

Mould O (2017) The Calais Jungle: A slum of London's making. CITY 21(3-4):

$388-404$. 
Pallister-Wilkins P (2019) The boundaries of Médecins Sans Frontières: Universalist humanitarianism in practice. In: Jones R (ed) Open Borders: For a Borderless World Athens, GA: University of Georgia Press, pp. 158-175.

Pollozek S and Passoth JH (2019) Infrastructuring European migration and border control: The logistics of registration and identification at Moria hotspot. Environment and Planning D: Society and Space online first.

Peck J and Theodore N (2016) Fast Policy: Experimental Statecraft at the Thresholds of Neoliberalism. Minneapolis: University of Minnesota Press.

Sassen S (2014) Expulsions: Brutality and Complexity in the Global Economy. Boston, MA: Harvard University Press.

Stierl M (2017) A fleet of Mediterranean border humanitarians. Antipode 50(3): 704-724.

Strauss K (2018) Labour geography 1: Towards a geography of precarity? Progress in Human Geography 42(4): 622-630.

Tazzioli M and Garelli G (2018) Containment beyond detention: The hotspot system and disrupted migration movements across Europe. Environment and Planning D: Society and Space. onlinefirst.

Triandafyllidou, A. (2014) Greek migration policy in the 2010s: Europeanization tensions at a time of crisis. Journal of European Integration 36(4): 409-425.

Vaughan-Williams N (2015) Europe's Border Crisis: Biopolitical Security and Beyond. Oxford: Oxford University Press.

Walters W (2012) Governmentality: Critical Encounters. London: Routledge.

Williams JM (2015) From humanitarian exceptionalism to contingent care: care and enforcement at the humanitarian border. Political Geography 47: 11-20. 